\title{
HIGH LINEARITY CMOS VARIABLE GAIN AMPLIFIER FOR UWB APPLICATIONS
}

\author{
I. L. Abdel-Hafez ${ }^{1}$, Y. A. Khalaf ${ }^{2}$, and F. A. Farag ${ }^{3, *}$ \\ Electronics and Communications Dept., Faculty of Engineering, \\ Zagazig University, Zagazig. Egypt
}

Received 11 November 2012; accepted 11 December 2012

\begin{abstract}
A large dynamic-range Variable Gain Amplifier (VGA) suitable for Ultra Wide Band (UWB) applications is presented. The VGA is composed of three programmable variable gain amplifier stages followed by an output buffer. Such wide bandwidth allows our proposed VGA to be used in multi-standard protocols. Power reduction is developed for the variable gain amplifier stages. Thorough analyses of the mid-band gain and noise are presented; and design tradeoffs are carefully handled. The VGA circuit is designed and simulated in $0.13 \mu \mathrm{m}$ IBM-CMOS process; the overall VGA with buffer consumes $25 \mathrm{~mA}$ from a $1.5 \mathrm{~V}$ supply. The VGA achieves $54.5 \mathrm{~dB}$ dynamic-range (DR), $17.6 \mathrm{dBm}$ IIP3, $-42.31 \mathrm{~dB}$ THD at peak-to-peak differential output voltage of $1 \mathrm{~V}$, and frequency $400 \mathrm{MHz}$. Moreover; the proposed circuit reports a good noise performance; the average integrated noise is $121.6 \mathrm{nV} / \sqrt{\mathrm{Hz}}$ at minimum gain of $-0.5 \mathrm{~dB}$.

Keywords: Automatic Gain Control (AGC), Variable Gain Amplifier (VGA), Digitally-controlled Variable Gain Amplifier (DVGA), Buffer, CMOS Analog Integrated Circuits, Low Voltage, Wide Bandwidth.
\end{abstract}

\section{Introduction}

The variable gain amplifier (VGA) is an indispensable building block to maximize the dynamic range of modern wireless communication systems [1], [2]. It is also widely used in medical equipment, hearing aids, disk drives, and so on [3]-[5]. A VGA is typically employed in a feedback loop to realize automatic gain control (AGC). The VGA of an AGC loop is used to control the transmission signal power or to adjust the received signal amplitude. There are two possible approaches to control the gain of the VGA. One is to build a discrete gain step VGA with a digital control signal [6], [7]; and the other is to design a VGA controlled by an analog gain- control signal [1]-[5]. Basically, digitallycontrolled VGAs use binary weighted arrays of resistors or capacitors for gain variations whereas analog-controlled VGAs adopt a variable transconductance or a variable resistance to control the gain. VGA circuits based on various technologies such as bipolar, BiCMOS, and CMOS have been introduced in the literature (e.g. [1]-[4]).

An important VGA requirement is to have a linear-in-decibel gain control characteristic, where the gain of the VGA changes exponentially with the control signal. The exponential gain control is required to achieve a wide dynamic-range and to maintain the AGC loop settling-time independent of the input signal level [8].

\footnotetext{
* Corresponding author.

E-mail: FFARAG@ZU.EDU.EG
} 
I. L. Abdel-Hafez et al, High Linearity Cmos Variable Gain Amplifier For Uwb Applications, pp. 577- 591

Another important aspect of a wideband VGA is to attain a large bandwidth. There are many systems for high-speed data communications such as ultra-wideband (UWB) systems, wireless local area networks (LANs), and Bluetooth. These systems provide a high data rate with relatively low power consumption in short-range wireless communications. For high-speed data communication, the bandwidth of a VGA must be very wide. Therefore, a wideband VGA is a key component.

While the density of the devices in Nanoscale technology is continually increasing, the interconnect lines across a chip increase significantly. Such long interconnects mandate the requirement of driving large capacitances [12]-[15]. Moreover, in some situations, circuits should have large fan-out. For these reasons, buffers are frequently used in analog and mixed signal circuits. Well-designed buffers should drive large capacitive load with wide bandwidth, minimum power consumption, low distortion, and low loading effect.

In this paper, we propose a new highly-linear wideband variable gain amplifier VGA. Our VGA parameters are compared to [17] - [20] to clarify the merits of the proposed circuit. It could obtain a high linearity, wide bandwidth, and large dynamic-range with large capacitive load and high swing.

Section II describes the architecture of the proposed wideband VGA supported by VGA-cell analysis. The design of the main blocks in the VGA is also explained. Noise and linearity performance of the VGA are analyzed. The implementation and simulation results are presented in Section III. The results are also analyzed and discussed. Conclusions are given in section IV.

\section{Wideband CMOS variable gain amplifier}

The proposed variable gain amplifier VGA, as shown in Fig. 1, consists of a number of variable gain amplifier stages (cells) followed by a buffer to drive the load. A binary control-word is used to control the gain of the variable gain amplifiers. The bandwidth of such variable gain amplifier cell should be so wide that the overall bandwidth of the whole VGA design is achieved. In this section, we introduce a three-stage configuration to implement the VGA with wide bandwidth, in which all VGA-cells are identical. The Variable Gain Amplifier (VGA)-cells implementation is considered and analyzed here. A novel VGA-cell, based on the Flipped Voltage Follower (FVF) [11] technique, is proposed with modifications to increase the headroom for the output swing and to enhance the transconductance of the VGA-cell. A new topology for the output buffer is also described and analyzed.

\subsection{Variable gain amplifier cell}

The complete circuit of the proposed VGA-cell is shown in Fig. 2. It demonstrates the signal-processing circuit, the common-mode-feedback circuit, and the bias circuit.

Journal of Engineering Sciences, Assiut University, Faculty of Engineering, Vol. 41, No. 2, March, 2013,E-mail address: jes@aun.edu.eg 
I. L. Abdel-Hafez et al, High Linearity Cmos Variable Gain Amplifier For Uwb Applications, pp. 577- 591

The VGA-cell consists of a CMOS differential amplifier, in which the $\mathrm{R}_{\mathrm{f}}$ and $\mathrm{R}_{\mathrm{s}}$ are used to vary the gain. $C s$ is inserted to widen out the bandwidth. $M_{1}$ and $\mathbf{M}_{2}$ are used to transfer the differential-voltage signal across $R_{s}$, which in turn is converted into differential-current flowing through $\mathrm{M}_{3}$ and $\mathrm{M}_{4}$. The differential signal current is mirrored to the output branches through $\mathrm{M}_{5}$ and $\mathrm{M}_{6} . \mathrm{M}_{7}$ and $\mathrm{M}_{8}$ are connected in Wilson currentmirror like-connectivity to define drain voltage of $\mathrm{M}_{1}$ and $\mathrm{M}_{2}$; and to provide larger headroom for the swing at these points in contrast to [11]. It also provides large output resistance at the output nodes $\mathrm{V}_{\mathrm{OP}}$ and $\mathrm{V}_{\mathrm{OM}}$. This VGA-cell is typically used to get the coarse and fine steps by controlling $\mathrm{R}_{\mathrm{s}}$ and $\mathrm{R}_{\mathrm{f}}$, respectively.

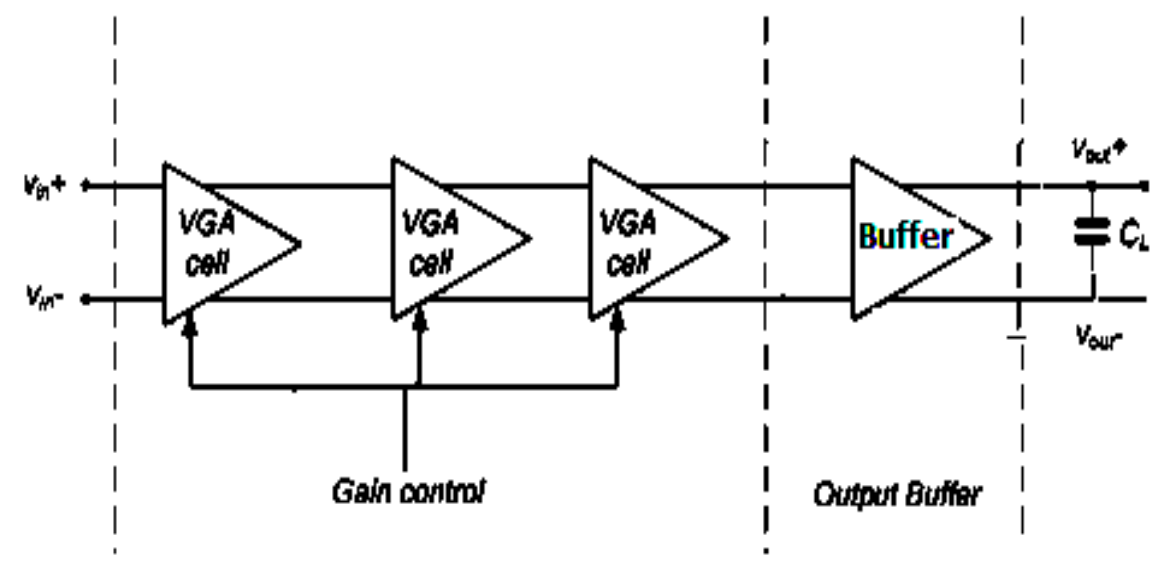

Fig. 1. Architecture of the overall VGA.

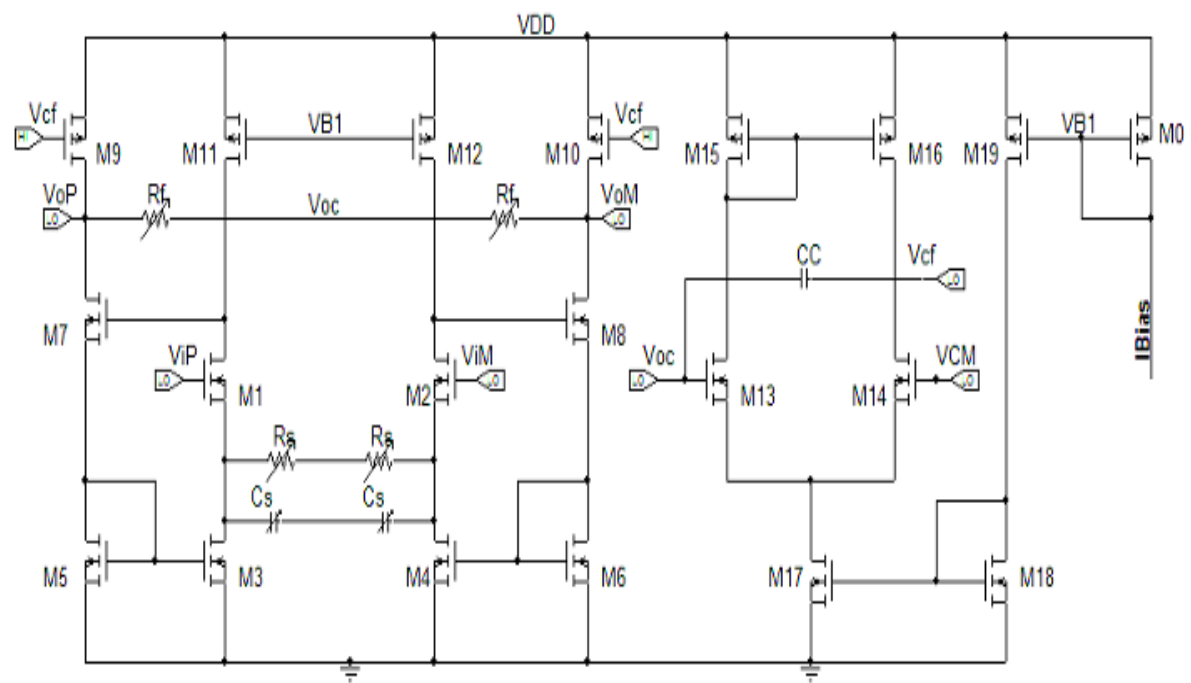

Fig. 2. Schematic diagram of the proposed VGA-cell.

Journal of Engineering Sciences, Assiut University, Faculty of Engineering, Vol. 41, No. 2, March, 2013,E-mail address: jes@aun.edu.eg 
I. L. Abdel-Hafez et al, High Linearity Cmos Variable Gain Amplifier For Uwb Applications, pp. 577- 591

The output voltage $\left(\mathrm{V}_{\mathrm{OP}}\right)$ half-circuit of the low-frequency small-signal model for the differential amplifier is shown in Fig. 3. The output voltage can be written as,

$$
V_{o P}=-g_{m 5} V_{g s 3}\left(R_{f} / / r_{o 9}\right)
$$

where $\mathrm{g}_{\mathrm{m} 5}$ is the transconductance of $\mathrm{M}_{5-6}, \mathrm{~V}_{\mathrm{gs} 3}$ is the voltage between gate and source of $\mathrm{M}_{3,4}$, and $\mathrm{r}_{09}$ is the output resistance of the transistor $\mathrm{M}_{9-10} . \mathrm{r}_{05}$ is ignored, compared to $1 / g_{m 5}$. The input voltage $V_{i P}$ of the differential amplifier is then,

$$
V_{i P}=V_{g s 1}+\left(I-g_{m 3} V_{g s 3}\right)\left(R_{s} / / r_{o 3}\right)
$$

where $\mathrm{I}$ is the current flowing into $\mathrm{r}_{\mathrm{o} 11}$.

$$
I=\frac{g_{m 1} r_{o 1} V_{g s 1}+g_{m 3}\left(R_{s} / / r_{o 3}\right) V_{g s 3}}{\left[\left(R_{s} / / r_{o 3}\right)+r_{o 1}+r_{o 11}\right]}
$$

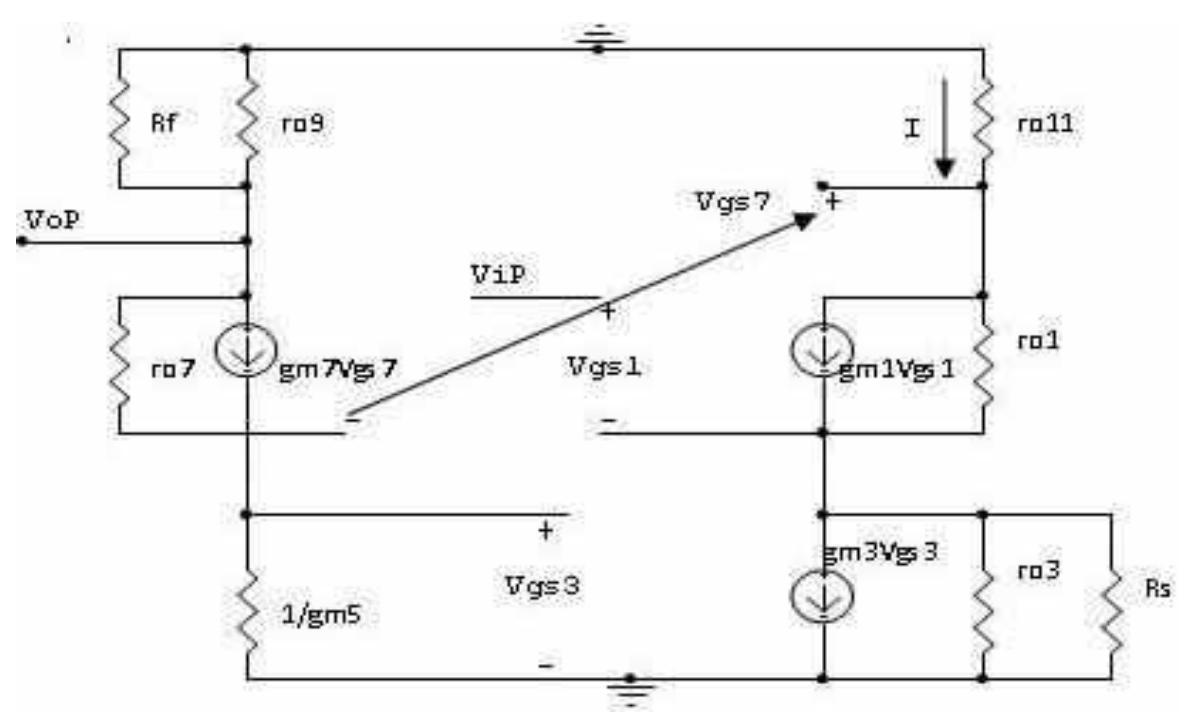

Fig. 3. Small-signal model of VGA circuit.

Applying KVL on the output branch, $\mathrm{V}_{\mathrm{gs} 7}$ can be calculated as,

$$
V_{g s 7}=\frac{\left\lfloor 1+g_{m 5}\left(r_{o 7}+\left(R_{f} / / r_{o 9}\right)\right\rfloor V_{g s 3}\right.}{g_{m 7} r_{o 7}}
$$

On the other hand, $\mathrm{V}_{\mathrm{gs} 3}$ can be related to $\mathrm{V}_{\mathrm{gs} 7}$ as,

$$
V_{g s 3}+V_{g s 7}=-I r_{o 11}
$$

Journal of Engineering Sciences, Assiut University, Faculty of Engineering, Vol. 41, No. 2, March, 2013,E-mail address: jes@aun.edu.eg 
I. L. Abdel-Hafez et al, High Linearity Cmos Variable Gain Amplifier For Uwb Applications, pp. 577- 591

Using equations (1) through (5) and doing some mathematical manipulation, we can calculate the output voltage gain $A_{V}$ :

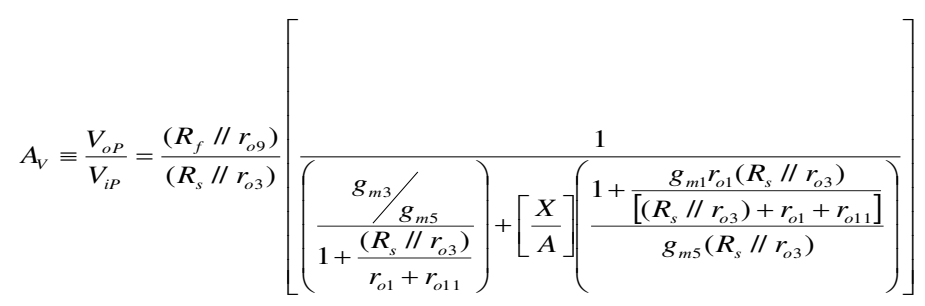

$\mathrm{r}_{\mathrm{o} 11}$ represents the resistance of the current source. If $\mathrm{r}_{\mathrm{o} 11}$ is relatively large, the output voltage gain $A_{V}$ can be approximated as,

$$
A_{V} \equiv \frac{V_{o P}}{V_{i P}}=\frac{\left(R_{f} / / r_{o 9}\right)}{\left(R_{s} / / r_{o 3}\right)} \frac{g_{m 5}}{g_{m 3}}
$$

It is worthy to mention that the effective transconductance seen by the degeneration resistance $R_{\mathrm{s}}$ is enhanced resulting in small voltage loss from the input to the source of $\mathrm{M}_{1}$. As seen from (7), the voltage gain $A_{V}$ is independent of transistor parameters except for $\mathrm{r}_{09}$, and $\mathrm{r}_{\mathrm{o} 3}$. In reality, $\mathrm{R}_{\mathrm{f}}$ and $\mathrm{R}_{\mathrm{s}}$ are chosen much smaller than $\mathrm{r}_{\mathrm{o} 9}$, and $\mathrm{r}_{\mathrm{o} 3}$, respectively. $A_{V}$ can then be approximately expressed as,

$$
A_{V} \cong \frac{R_{f}}{R_{S}} n
$$

where $\mathrm{n}$ is the ratio $\left(\mathrm{g}_{\mathrm{m} 5} / \mathrm{g}_{\mathrm{m} 3}\right)$. As a result, the gain of the circuit is stable across process corner variations. In our design, $n$ is chosen to be equal to unity whereas the ratio $R_{f} / R_{s}$ should be designed to implement linear-in-dB gain.

\subsection{Noise analysis of the proposed VGA}

Half of the differential amplifier with equivalent noise sources is shown in Fig. 4. The drain-source noise current generators of MOSFETs are considered. For noise sources of $M_{3,4}$ and the resistance $R_{s}$, the total output noise can be calculated as [20],

$$
\overline{v_{n, \text { out }}^{2}}=\frac{g_{m 7}^{2}\left(R_{f} / / r_{o 9}\right)^{2} a^{2}}{\left(1+\frac{a g_{m 3} g_{m 7}}{g_{m 5}}\right)^{2}} i_{n}^{2}
$$

where, $a=\left(\frac{g_{m 5^{r} o 11}}{g_{m 5}+g_{m 7}}\right)\left(\frac{g_{m 1} R_{s}}{1+g_{m 1} R_{s}}\right)$ and,$i_{n}^{2}=\overline{i_{n, M 3}^{2}}+\overline{i_{n, R_{s}}^{2}} ; \mathrm{g}_{\mathrm{mi}}$ and $\mathrm{r}_{\mathrm{oi}}$ are transconductance and output resistance of the transistor $\mathrm{M}_{\mathrm{i}}$.

Journal of Engineering Sciences, Assiut University, Faculty of Engineering, Vol. 41, No. 2, March, 2013,E-mail address: jes@aun.edu.eg 


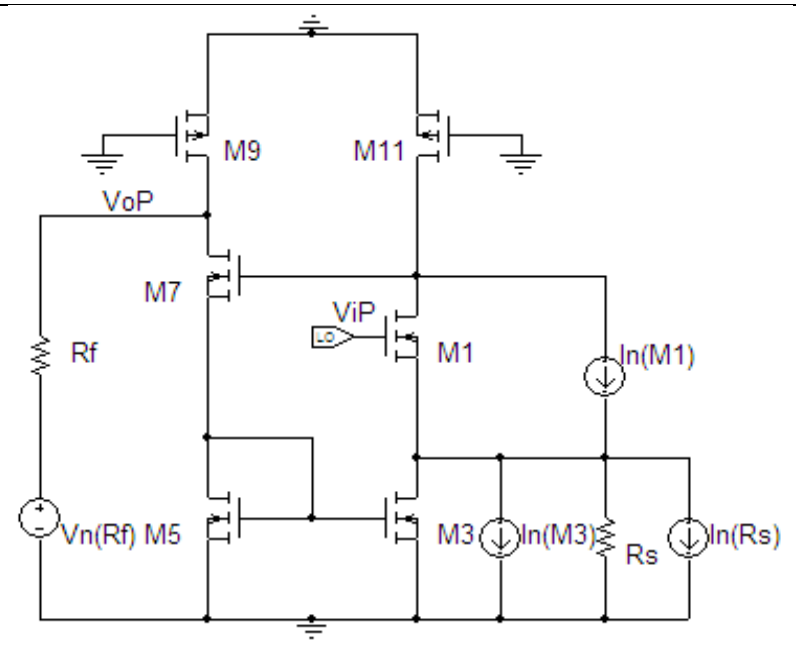

Fig. 4. Calculation of the input-referred noise of the proposed VGA-cell

Referring to the input port, $\overline{v_{\mathrm{n}, \mathrm{in}}^{2}}=\frac{\overline{v_{n, \text { out }}^{2}}}{\left|A_{V o}\right|^{2}}$, the input referred noise due to $\mathbf{M}_{3,4}$ and $\mathrm{R}_{\mathrm{s}}$ can be approximately expressed as:

$$
\overline{v_{n, i n}^{2}}=\left(\frac{1}{1+\frac{g_{m 7}}{g_{m 5}}}\right)^{2}\left(\frac{g_{m 1} R_{S}}{1+g_{m 1} R_{S}}\right)^{2} R_{S}^{2} \overline{i_{n}^{2}}
$$

The noise due to input transistor $\mathrm{M}_{1}$ and resistance $\mathrm{R}_{\mathrm{f}}$ can be added to estimate the total input-referred noise as,

$$
\begin{aligned}
& \overline{v_{n, \text { in }(\text { tot })}^{2}}=\frac{1}{g_{m 1}^{2}} \overline{i_{n 1}^{2}}+\left(\overline{v_{n, R_{f}}^{2}}+\overline{v_{n, \text { out }}^{2}}\right)\left|\frac{1}{A_{V 0}}\right|^{2} \\
& \text { where, } \overline{i_{n, M_{i}}^{2}}=4 k T\left(\frac{2}{3} g_{m i}\right) \Delta f+K \frac{I_{D i}^{a}}{f} \Delta f, \overline{i_{n, R_{s}}^{2}}=\frac{4 k T}{R_{S}} \Delta f, \text { and } \overline{v_{n, R_{f}}^{2}}=4 k T R_{f} \Delta f .
\end{aligned}
$$

At low-gain settings, $\mathrm{A}_{\mathrm{v} 0}$ becomes small and so the last term in (11), defined by (10), dominates the noise performance of the circuit. As a result, $\mathrm{R}_{\mathrm{S}}$ should be chosen small enough for good noise performance. In contrast, at large-gain settings, noise performance

Journal of Engineering Sciences, Assiut University, Faculty of Engineering, Vol. 41, No. 2, March, 2013,E-mail address: jes@aun.edu.eg 
I. L. Abdel-Hafez et al, High Linearity Cmos Variable Gain Amplifier For Uwb Applications, pp. 577- 591

is dominated by the first term in (11) (input transistors $\mathrm{M}_{1}$ and $\mathrm{M}_{2}$ ) and consequently $\mathrm{g}_{\mathrm{m} 1}$ should be maximized.

\subsection{Output CMOS Buffer}

Our proposed buffer circuit [10] is shown in Fig. 5. The circuit has achieved large transconductance without increasing the aspect ratio of the main differential transistors $\mathrm{M}_{1}$ and $\mathrm{M}_{2}$. The basic idea of the buffer is to improve the bandwidth based on the Flipped Voltage Follower (FVF) by enhancing the transconductance of $\mathrm{M}_{3}\left(\mathrm{M}_{4}\right)$ through the feedback loop $\mathrm{M}_{1}, \mathrm{M}_{7}$, and $\mathrm{M}_{5}\left(\mathrm{M}_{2}, \mathrm{M}_{8}\right.$, and $\left.\mathrm{M}_{6}\right)$.

The circuit is biased by two pairs of current sources $\left(\mathrm{M}_{9}\right.$ and $\left.\mathrm{M}_{10}\right)$ and $\left(\mathrm{M}_{11}\right.$ and $\left.\mathrm{M}_{12}\right)$; the former pair supplies low current to the main differential transistors, and so small loading-effect is observed at the input of the buffer. The latter pair is used to enhance the required current needed for driving large capacitive load. The feedback is accomplished through the level shifter $\mathrm{M}_{5}$ and $\mathrm{M}_{7}\left(\mathrm{M}_{6}\right.$ and $\left.\mathrm{M}_{8}\right)$ to increase the swing headroom for $\mathrm{M}_{1}$ $\left(\mathrm{M}_{2}\right)$, and consequently the linearity.

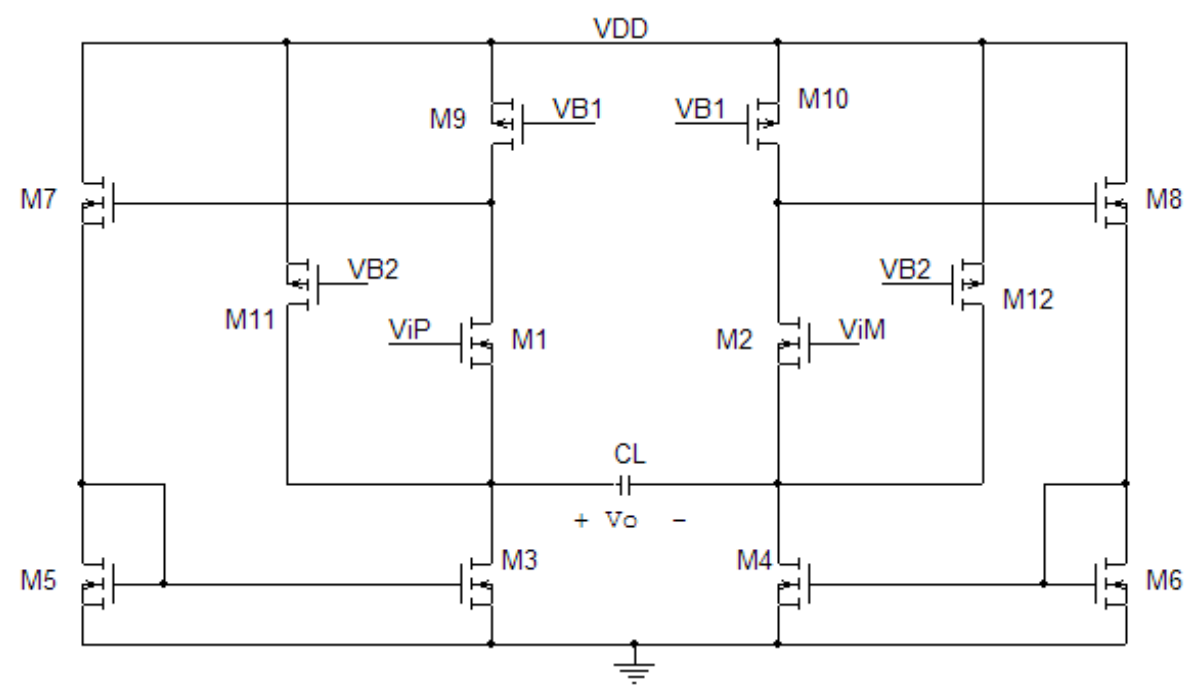

Fig. 5. Proposed buffer circuit [10]

The output voltage $\left(V_{\mathrm{oP}}\right)$ half-circuit of the small-signal model is shown in Fig. 6 (half of the circuit is shown for clarity). One-half of the circuit is only considered for simplicity without loss of generality.

Journal of Engineering Sciences, Assiut University, Faculty of Engineering, Vol. 41, No. 2, March, 2013,E-mail address: jes@aun.edu.eg 


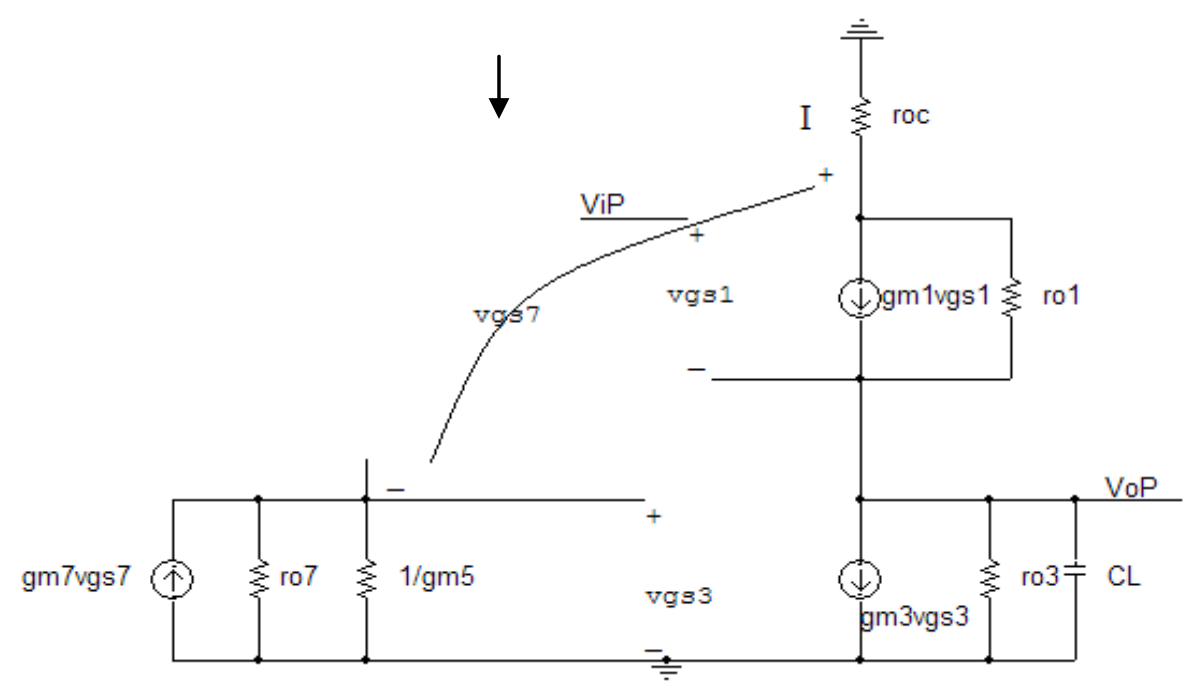

Fig. 6. Small-signal model of the proposed buffer

A similar analysis, to what has been done in Section II.A, can be conducted to calculate the output voltage gain $A_{V}$,

$$
A_{v}=\frac{A_{O}}{1+j \omega \frac{C_{L}}{g_{m e f f}} A_{O}}
$$

Where $A_{o}$ is the DC gain defined by,

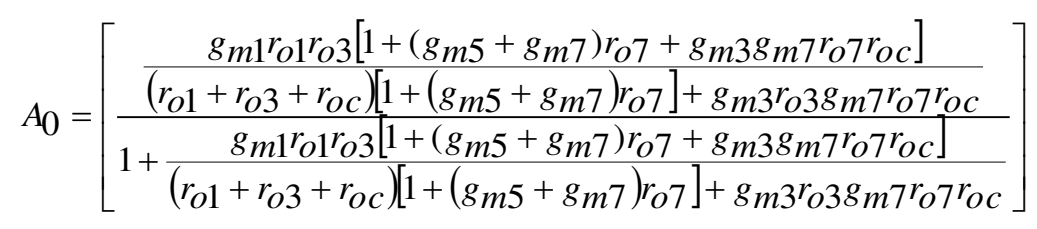

and

$$
g_{\text {meff }}=\left[\frac{g_{m 1} r_{o 1} r_{o 3}\left[1+\left(g_{m 5}+g_{m 7}\right) r_{o 7}+g_{m 3} g_{m 7} r_{o 7} r_{o c}\right]}{r_{o 3}\left(r_{o 1}+r_{o c}\right)\left[1+\left(g_{m 5}+g_{m 7}\right) r_{o 7}\right]}\right]
$$

Journal of Engineering Sciences, Assiut University, Faculty of Engineering, Vol. 41, No. 2, March, 2013,E-mail address: jes@aun.edu.eg 
I. L. Abdel-Hafez et al, High Linearity Cmos Variable Gain Amplifier For Uwb Applications, pp. 577- 591

If $r_{\mathrm{oc}}, \mathrm{r}_{\mathrm{o} 1}$ and $\mathrm{r}_{\mathrm{o} 7}$ are very large and the term $\mathrm{r}_{\mathrm{o} 3} \mathrm{~g}_{\mathrm{m} 3}$ is much greater than unity, the effective transconductance can be reduced to,

$$
g_{m e f f}=g_{m 1}\left[1+\frac{g_{m 3} g_{m 7} r_{O C}}{\left(g_{m 5}+g_{m 7}\right)}\right]
$$

From (15), the overall transconductance is approximately improved by the closed loop gain from input to the ac current of $\mathrm{M}_{3}-\mathrm{M}_{4}$, through $\left(\mathrm{M}_{1}, \mathrm{M}_{7}, \mathrm{M}_{5}\right.$, and $\left.\mathrm{M}_{3}\right)$, which is very large. The overall transconductance was improved by a factor proportional to approximately $\mathrm{g}_{\mathrm{m}} \mathrm{r}_{\mathrm{oc}}$ without increasing the basic transistor size. On the other hand, the THD is superior for our proposed cell compared to the FVF cell.

\section{VGA implementation and simulation results}

\subsection{Variable gain amplifier}

The VGA is implemented in $0.13-\mu \mathrm{m}$ IBM CMOS process. The design equations, derived in the previous section, are used to guide our design. The VGA achieves the required bandwidth of $400 \mathrm{MHz}$ with gain varying from $-0.5 \mathrm{~dB}$ to $54 \mathrm{~dB}$ using 5-bits control-word. It consists of three identical VGA-cells. $R_{s}$ is used to generate coarse-gain steps of $16 \mathrm{~dB}$ each whereas $R_{\mathrm{f}}$ is used to generate fine-gain steps of $2 \mathrm{~dB}$ each. Compensation capacitor array $C_{s}$ has been also used in parallel with $R_{s}$ to introduce a programmable zero into the transfer function that can be employed to widen out the bandwidth at large gain settings. The overall simulated variable gain amplifier current dissipation is $21 \mathrm{~mA}$.

Fig. 7 shows the gain plot versus gain-control word for the simulated and analytical results equation (6); the gain is clearly linear-in-dB. There is also good agreement between analytical and simulated plots across wide gain dynamic range from $-0.5 \mathrm{~dB}$ up to $54 \mathrm{~dB}$. The insensitivity to process variation has been also studied, where there are only $0.5 \mathrm{~dB}$ deviations from the results of the typical mean process parameters.

Fig. 8 shows the frequency response for different gain settings. The bandwidth decreases as the gain increases, however bandwidth could be kept at its minimum value of $400 \mathrm{MHz}$ by controlling the zero location without significant increase in power consumption. While the bandwidth at the maximum gain can achieve $400 \mathrm{MHz}$, the bandwidth at the minimum gain extends to $2 \mathrm{GHz}$. It is also worthy to mention that the peak occurs outside the bandwidth of interest.

The linearity performance of VGA is characterized by two-tone IIP3 test. It was measured by applying two tones of $100 \mathrm{MHz}$ and $120 \mathrm{MHz}$ at the lowest gain mode. The result is shown in Fig. 9 where IIP3 is equal to17.6dBm. Table 1 compares our work against others' work in the literature. The GBW/power is taken as a figure of merit for a reasonable comparison. Our VGA shows the highest figure-of-merit. The circuit also

Journal of Engineering Sciences, Assiut University, Faculty of Engineering, Vol. 41, No. 2, March, 2013,E-mail address: jes@aun.edu.eg 
I. L. Abdel-Hafez et al, High Linearity Cmos Variable Gain Amplifier For Uwb Applications, pp. 577- 591

shows reasonable noise performance, which can be certainly improved at the expense of higher power consumption.

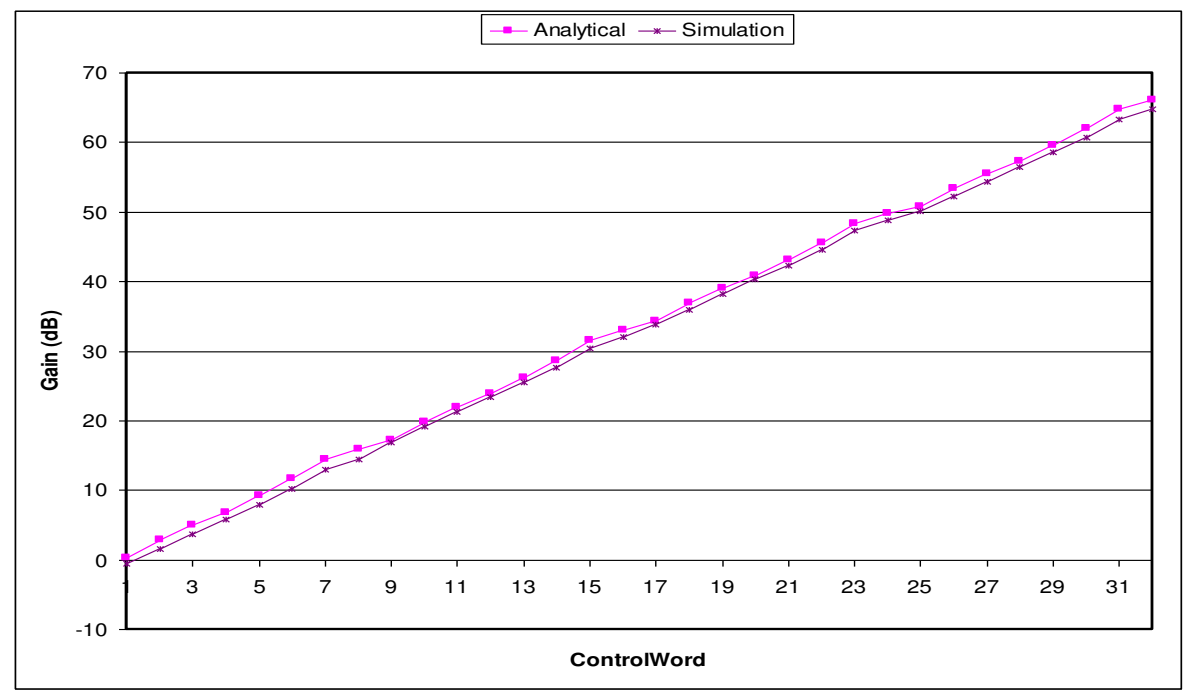

Fig. 7. Linear-in-dB gain versus control word

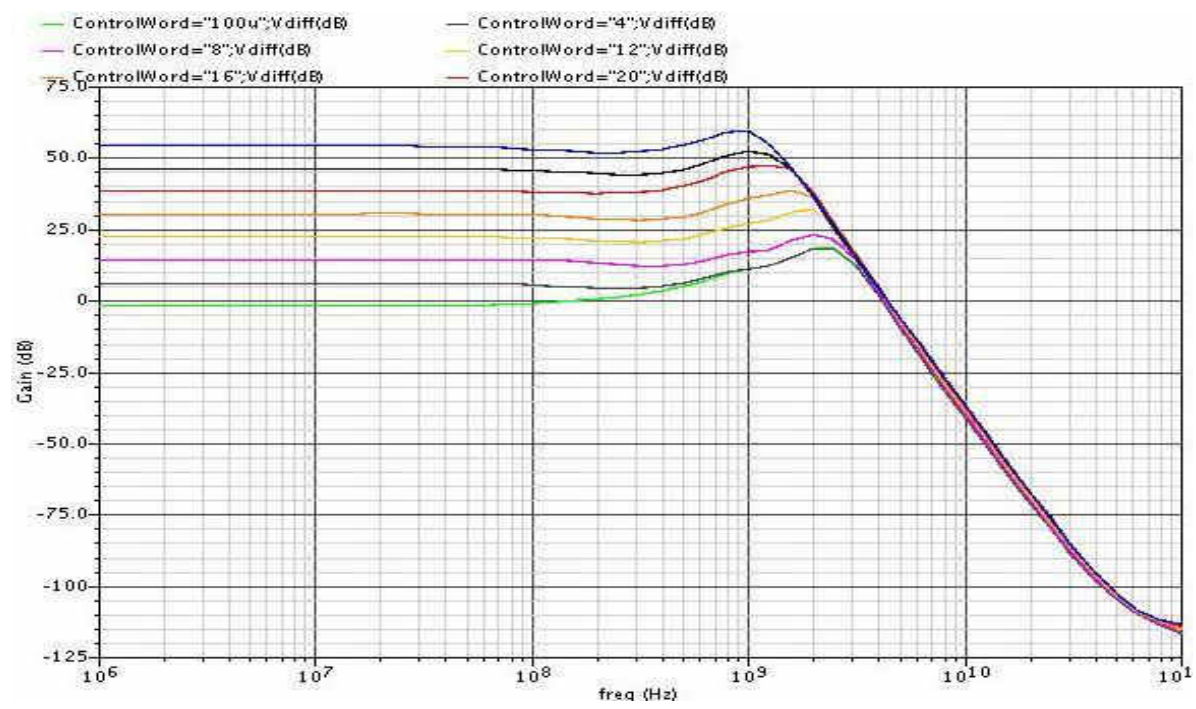

Fig. 8. Gain versus frequency for different gain settings

Journal of Engineering Sciences, Assiut University, Faculty of Engineering, Vol. 41, No. 2, March, 2013,E-mail address: jes@aun.edu.eg 
I. L. Abdel-Hafez et al, High Linearity Cmos Variable Gain Amplifier For Uwb Applications, pp. 577- 591

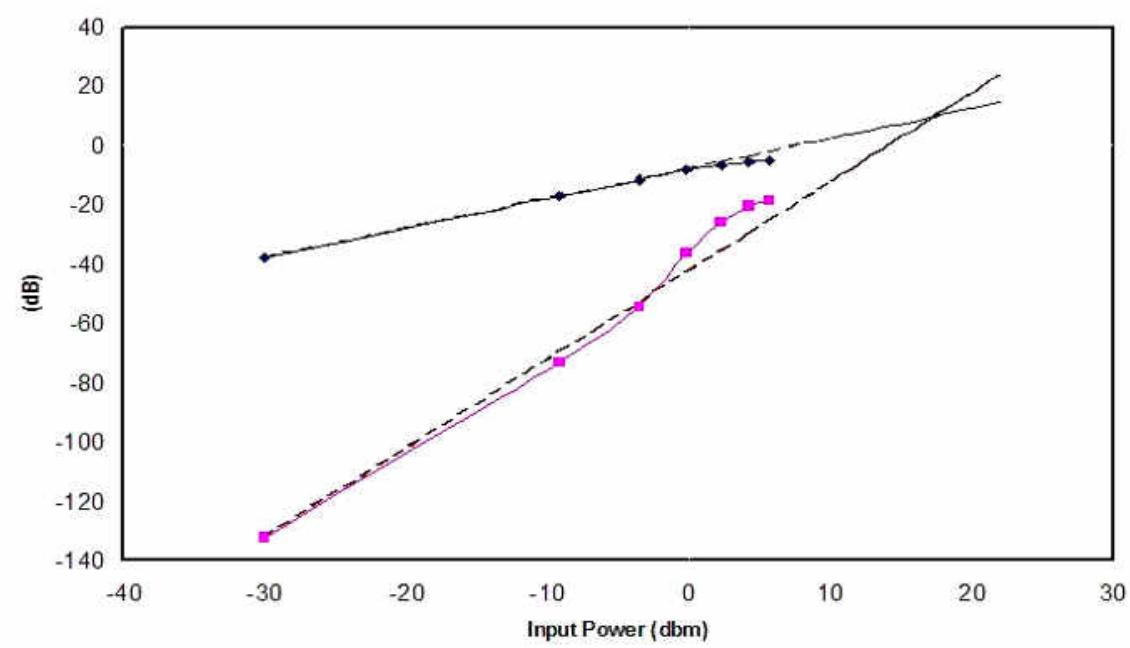

Fig. 9. The IIP3 at the lowest gain mode

Table 1

Performance summary and comparison

\begin{tabular}{|c|c|c|c|c|c|}
\hline Parameters & [17] & [18] & [19] & [20] & This Work \\
\hline Technology & $0.18 \mu \mathrm{m}$ & $0.18 \mu \mathrm{m}$ & $0.18 \mu \mathrm{m}$ & $0.13 \mu \mathrm{m}$ & $0.13 \mu \mathrm{m}$ \\
\hline Supply voltage & $1.8 \mathrm{~V}$ & $1.8 \mathrm{~V}$ & $1.8 \mathrm{~V}$ & $1.5 \mathrm{~V}$ & $1.5 \mathrm{~V}$ \\
\hline Bandwidth (MHz) & 450 & 650 & $\begin{array}{r}400 \\
@ 54 \mathrm{~dB}\end{array}$ & $183-548$ & 1500 \\
\hline Gain range & $\begin{array}{l}3-47 \\
\mathrm{~dB}\end{array}$ & $\begin{array}{r}0.7- \\
60.7 \mathrm{~dB}\end{array}$ & $\begin{array}{l}-30-65 \\
\mathrm{~dB}\end{array}$ & $-5-65 \mathrm{~dB}$ & $-0.5-54 \mathrm{~dB}$ \\
\hline IIP3 & $20 \mathrm{dBm}$ & & & & $17.6 \mathrm{dBm}$ \\
\hline Current dissipation & $15 \mathrm{~mA}$ & $8.9 \mathrm{~mA}$ & $12.2 \mathrm{~mA}$ & $13.4 \mathrm{~mA}$ & $21 \mathrm{~mA}$ \\
\hline $\mathrm{P}_{\mathrm{diss}}(\mathrm{mW})$ & 27 & 16.02 & 21.96 & 20.1 & 31.5 \\
\hline $\begin{array}{l}\text { THD @ freq=400MHz } \\
\& \mathrm{~V}_{\text {od(p-p) }}=1 \mathrm{~V}\end{array}$ & & & & & $\begin{array}{c}-49.47 \mathrm{~dB} @ 54 \\
\mathrm{~dB} \\
-43.26 \mathrm{~dB} @-0.5 \\
\mathrm{~dB}\end{array}$ \\
\hline Input referred noise & & & & & $\begin{array}{c}121.6 \mathrm{nV} / \sqrt{ } \mathrm{Hz} @ \\
-0.5 \mathrm{Db}\end{array}$ \\
\hline
\end{tabular}

Journal of Engineering Sciences, Assiut University, Faculty of Engineering, Vol. 41, No. 2, March, 2013,E-mail address: jes@aun.edu.eg 
I. L. Abdel-Hafez et al, High Linearity Cmos Variable Gain Amplifier For Uwb Applications, pp. 577- 591

\begin{tabular}{llllll}
\hline \hline Parameters & {$[17]$} & {$[18]$} & {$[19]$} & {$[20]$} & This Work \\
\hline $\begin{array}{l}\text { GBW/Power(MHz/m } \\
\text { W) }\end{array}$ & 7518 & 48507 & 53083 & 48438 & 56103 \\
\hline \hline
\end{tabular}

\subsection{The overall $V G A$}

Table 2 summarizes the crucial simulation results of the overall variable gain amplifier with the output buffer at maximum and minimum gain settings. The buffer is loaded with a capacitive single-ended load of $2 \mathrm{pF}$. The noise performance of the circuit is dominated by the VGA, Table 2; the buffer noise is insignificant because of its large transconductances and so small input referred noise.

Table 2

Summary of the simulation results of the overall VGA

\begin{tabular}{lcc}
\hline \hline \multicolumn{1}{c}{ Parameters } & $@-0.5 \mathrm{~dB}$ & $@ 54 \mathrm{~dB}$ \\
\hline Bandwidth $(\mathrm{GHz})$ & 3.5 & 1.5 \\
Average Integrated Noise $(\mathrm{nV} / \sqrt{\mathrm{Hz}})$ & 121.6 & 17.4 \\
THD $(\mathrm{dB}) @ 400 \mathrm{MHz}$ and $\mathrm{V}_{\text {odp-p }}=1 \mathrm{~V}$. & -40.04 & -42.31 \\
Power dissipation $(\mathrm{mw})$ & & 37.5 \\
\hline \hline
\end{tabular}

Fig. 10 shows the frequency response of the overall VGA at the extreme gain settings. As seen from Fig. 10, the frequency response extends for more than $400 \mathrm{MHz}$. Although the small-signal bandwidth can be as large as $1.5 \mathrm{GHz}$, the effective bandwidth is limited to $400 \mathrm{MHz}$ only, for output voltage swing of $1 \mathrm{~V}_{\mathrm{dpp}}$ with the aforementioned loading, owing to the slew-rate limitation.

\section{Conclusions}

This paper presents a low-voltage CMOS VGA. It achieved wide bandwidth over wide dynamic gain range from $-0.5 \mathrm{~dB}$ to $54 \mathrm{~dB}$. With this circuit topology, the gain and bandwidth can be programmed independently. The circuit has been designed and implemented using $0.13 \mu \mathrm{m}$ IBM-CMOS process with supply voltage of $1.5 \mathrm{~V}$ and power dissipation of $37.5 \mathrm{~mW}$ to drive $2 \mathrm{pF}$ single-ended capacitive loads.

Journal of Engineering Sciences, Assiut University, Faculty of Engineering, Vol. 41, No. 2, March, 2013,E-mail address: jes@aun.edu.eg 
I. L. Abdel-Hafez et al, High Linearity Cmos Variable Gain Amplifier For Uwb Applications, pp. 577- 591

This VGA can be applied to various applications, such as high performance industrial systems and baseband circuits in multi-standard wireline and wireless communications with wide bandwidth.

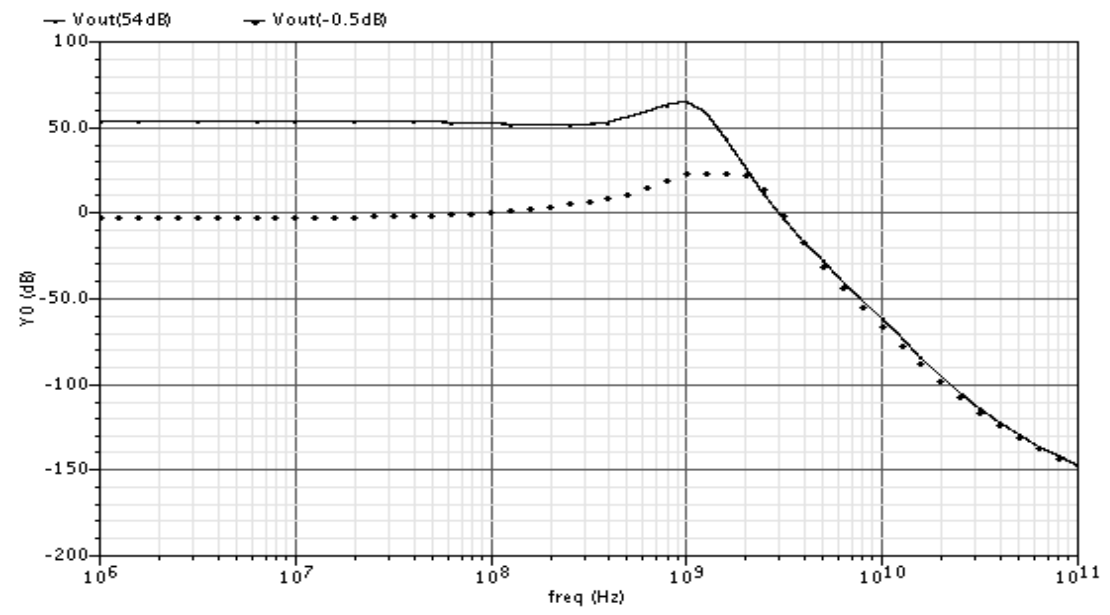

Fig. 10. Frequency response for the overall VGA

\section{Acknowledgment}

The authors gratefully acknowledge the technical support of the MOSIS Company for their support and provision of the design kit used in this work.

\section{References}

[1] J. K. Kwon, K. D. Kim, W. C. Song, and G. H. Cho, "Wideband high dynamic range CMOS variable gain amplifier for low voltage and low power wireless applications," Electron. Lett., vol. 39, no. 10, pp. 759-760, Mar. 2003.

[2] T. Yamaji, N. Kanou, and T. Itakura, "A temperature-stable CMOS variable-gain amplifier with 80-dB linearly controlled gain range," IEEE J. Solid-State Circuits, vol. 37, no. 5, pp. 553-558, May 2002.

[3] W. M. Christopher, "A variable gain CMOS amplifier with exponential gain control," in VLSI Circuits Tech. Dig. Symp., pp. 146-149, Jun. 2000.

[4] P. Huang, L. Y. Chiou, and C. K.Wang, "A 3.3-V CMOS wideband exponential control variable-gain-amplifier,” in Proc. IEEE Int. Circuits Syst. Symp., pp. I-285-I-288, May 1998.

[5] M. M. Green and S. Joshi, "A 1.5 V CMOS VGA based on pseudo differential structures," in Proc. IEEE Int. Circuits Syst. Symp., pp. IV-461-IV-464, May 2000.

[6] P. Orsatti, F. Piazza, and Q. Huang, “A 71-MHz CMOS IF-baseband strip for GSM,” IEEE J. Solid-State Circuits, vol. 35, no. 1, pp. 104-108, Jan. 2000.

Journal of Engineering Sciences, Assiut University, Faculty of Engineering, Vol. 41, No. 2, March, 2013,E-mail address: jes@aun.edu.eg 
I. L. Abdel-Hafez et al, High Linearity Cmos Variable Gain Amplifier For Uwb Applications, pp. 577- 591

[7] H. O. Elwan and M. Ismail, "Digitally programmable decibel-linear CMOS VGA for lowpower mixed-signal applications," IEEE Trans. Circuits Syst. II, Analog Digit. Signal Process., vol. 47, no. 5, pp. 388-398, May 2000.

[8] J. M. Khoury, "On the design of constant settling time AGC circuit," IEEE Trans. Circuits Syst. II, Analog Digit. Signal Process., vol. 45, no. 3, pp. 283-294, Mar. 1998.

[9] I. L. Abdel-Hafez, Y. A. Khalaf, and F. A. Farag, "CMOS buffer amplifier for wide bandwidth applications," IEEE International Conference on Design and Technology of Integrated Systems in NanoScale Era (DTIS'7), pp. 56-59, September 2007.

[10] R. G. Carvajal, J. Ramírez-Angulo ,A. J. López-Martín, A. Torralba, J. A. G. Galán, A. Carlosena , and F. M. Chavero," The flipped voltage follower: a useful cell for low-voltage low-power circuit design," IEEE transactions on circuits and systems I: vol. 52, no. 7, July 2005.

[11] J. J. F. Rijns, "CMOS low-distortion high-frequency variable-gain amplifier," IEEE journal of solid-state circuits, vol. 31, no. 7, July 1996.

[12] K. Moolpho and J. Ngarmnil, "Low voltage high-performance class-AB FGMOS buffer," Circuits and Systems, APCCAS 2006. IEEE Asia Pacific Conference, pp.1779 - 1782, Dec. 2006.

[13] C.W. Lu and Y. C. Huang, "1.5 V large-driving class-AB buffer amplifier with quiescent current control," Electronics Letters 8th, Vol. 40 No. 1, Jan. 2004

[14] S. Baswa, A.J. Lo'pez-Martı'n, R.G. Carvajal, and J. R. 'rez-Angulo, "Low-voltage powerefficient adaptive biasing for CMOS amplifiers and buffers," Electronics Letters 19th, Vol. 40 No. 4, Feb. 2004.

[15] K. Hadidi, J. Sobhi, A. Hasankhaan, D. Muramatsu, and T. Matsumoto, "A novel highly linear CMOS buffer," Electronics, Circuits and Systems, 1998 IEEE International Conference on Volume 3, 7-10, PP. 369 - 371 vol.3 , Sept. 1998.

[16] S. Jang, S. S. Lee, S.-S. Choi, and K. C. Lee,"A CMOS Baseband Receiver for Wireless Broadband Communications," Feb. 7-10, 2010 ICACT 2010.

[17] Y. J. The, C. F. Chung, and M. A. Arasu, "A 3-47dB gain, +20dBm IIP3, 400MHz VGA for a pulse-based UWB in $0.18 \mu \mathrm{m}$ CMOS," ISIC 2009.

[18] J. Cheng, F.Y. Huang, L.H. Wu, Y. Tian, and N. Jiang, "A High-linearity, 60-dB Variable Gain Amplifier with Dual DC-offset Cancellation for UWB Systems," Sept. 4, WICOM.2009.

[19] C. T. Fu and H. Luong "A CMOS linear-in-dB high-linearity variable-gain amplifier for UWB receivers," Solid-State Circuits Conference, 2007. ASSCC ' 07.

[20] I. L. Abed-Hafez, " Design of RF -CMOS IC" M. Sc. Thesis, Zagazig University, 2009.

Journal of Engineering Sciences, Assiut University, Faculty of Engineering, Vol. 41, No. 2, March, 2013,E-mail address: jes@aun.edu.eg 
I. L. Abdel-Hafez et al, High Linearity Cmos Variable Gain Amplifier For Uwb Applications, pp. 577- 591

مكبر جها (CMOS) ذو عامل كسب متغير لتطبيقات النطاق الترددي الواسع (UWB) عالي الخطية

ملخص:

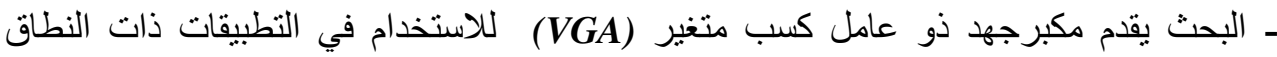

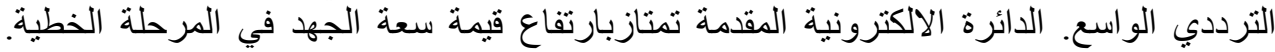

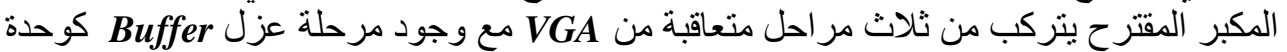

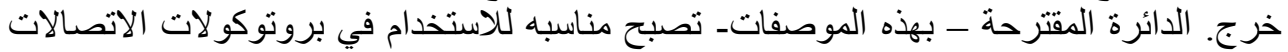

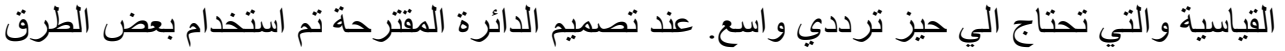

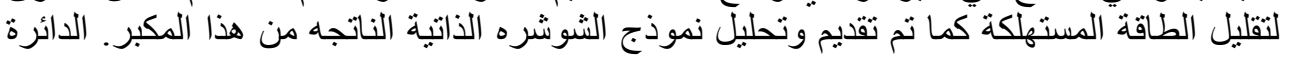

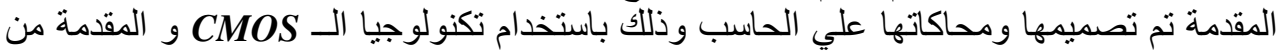
شركة

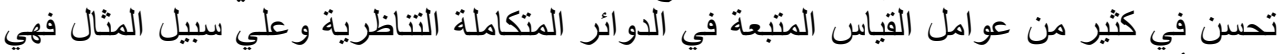

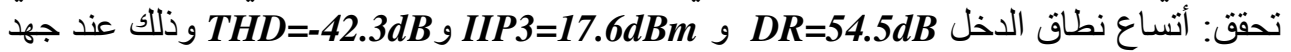
دخل 1,0 من القمة للقمة وتردد يساوي (400 مجاهرتز). و وعلاوة علي ذللك فأن الدائرة (VGA)

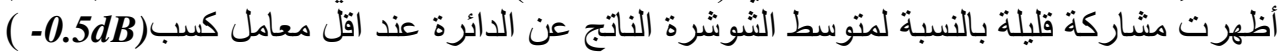

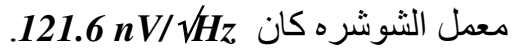

Journal of Engineering Sciences, Assiut University, Faculty of Engineering, Vol. 41, No. 2, March, 2013,E-mail address: jes@aun.edu.eg 